\title{
A Simple Technique for the Identification of Environmental DNA (eDNA) in the Water Samples
}

Chitra K. Y.

Assistant Professor, Environmental Biology and Toxicology Laboratory, Department of Zoology, University College for Women, Osmania University, Telangana, India

\section{ABSTRACT}

Article Info

Volume 8, Issue 4

Page Number : 77-80

Publication Issue :

July-August-2021

\section{Article History}

Accepted : 06 July 2021

Published: 13 July 2021
The environmental DNA (eDNA) is the DNA that is shed by the organisms in their environment by different ways viz., mucous, faeces, skin, eggs, sperms and also when these organisms die due to natural death or disease. The eDNA will persist for several days. Identification of eDNA is a useful method of determining the organisms present in an aquatic environment like amphibians, reptiles, fishes, insects and larval forms of some of these organisms. By analysing the e-DNA it is possible to monitor the species distribution in water bodies like lakes and ponds simply by collecting a sample of water. The technique can be applied for the survey of the water bodies on a large scale for the genomic, taxonomic as well as pollutional studies. The DNA isolation procedures that are available are laborious and time consuming. Therefore, during the present study, a simplified method was devised i. e., isolation of eDNA with ethanol after which Feulgen stain was applied to identify and confirm it, as it is an easy method before proceeding to work with the isolated eDNA using other techniqnies for further studies. The Feulgen method is used for the selective staining and the localisation of the DNA in the tissues but is adopted during the present study for the water samples for quick identification of eDNA. The smear of eDNA stained with Feulgen showed dark pink or magenta colour under the microscope where it was concentrated but stained lightly when dispersed and fragmented as observed in the present study. Further studies of the isolated eDNA are in progress in our laboratory for quantifying and sequencing eDNA using latest techniques like next generation sequencing for the identification of fish species in the lakes.

Keywords : eDNA, Lakes, Feulgen Stain, Biodiversity, Taxonomy, Genetics.

\section{INTRODUCTION}

The e-DNA is the DNA that can be obtained from the habitat in which the organisms live that shed it in the environment through the skin, mucous, faeces, eggs, sperms etc and also from the dead organisms due to natural death and disease. The eDNA will persist for several days and can be identified from a sample of 
water first and then be analysed by different techniques for various studies like genomic, taxonomic, distribution of species in a particular environment and pollution effects. Identification of eDNA is a useful method of determining the organisms present in an aquatic environment like fishes (Didier et. al, 2019). Other organisms like amphibians, reptiles, insects and larval forms of some of these organisms can also be identified using eDNA. The eDNA was found to be a useful tool in ecology and conservation biology (Kingsly C Beng \& Richard T. Corlett, 2020). For any study related to genetics, extraction of DNA is a must. One of the important factors for such studies is the quantity and quality of the DNA which inturn depends on the methods used for its extraction therefore, prior to the staining, the eDNA was treated with ethanol. Instead of laborious and cumbersome procedures, the simple method of Feulgen was applied which was devised by standardising taking different volumes of the isolated DNA sample (Concentrated) and the Feulgen stain in a certain proportion to get good results. The stain was discovered by Robert Feulgen in 1924 used for staining the chromosome material histologically. The eDNA is identified in the same manner as it does for the localization of tissue DNA with Feulgen stain, a pink or magenta colour is seen when observed under the microscope. The technique is useful to test the different samples simultaneously in less time. Therefore, an attempt was made to use Feulgen method in the present study for the presence of eDNA in the water samples.

\section{METHODS AND MATERIAL}

The eDNA kits if available can be used, alternately ethanol may be used to precipitate out DNA from the water samples collected from the field in $250-500 \mathrm{ml}$ stoppered bottles. The water samples from the local lakes were collected for the present study. After filtering the samples to remove any debris that might interfere with testing, the samples were measured for the required amount, twice the volume of ethanol was added immediately to it. The samples treated with ethanol precipitates out the eDNA and preserves it also(Genetic education, 2018). Other reagents like sodium chloride and sodium citrate buffer mixture $(0$. $15 \mathrm{M}$ and $0.015 \mathrm{M}$ respectively) followed by addition of $2 \mathrm{M}$ sodium chloride, can also be used to isolate the eDNA.

The sample is allowed to stand for atleast 4-5 hours for the precipitated eDNA to settle at the bottom of the stoppered bottle which is a creamy layer differentiating it from the top water layer. With the help of a dropper a few drops of the creamy layer was collected in a test tube from which a small quantity is spread on a slide as a smear. The method of staining involves treating the slide with $1 \mathrm{~N} \mathrm{HCl}(5 \mathrm{~min})$ in a boiling water bath at $60^{\circ} \mathrm{C}$. A few drops of commercially available Schiff's reagent was then added and kept for 30min at room temperature, the slide was rinsed with potassium metabisulphite and observed under the microscope . (if reagent is not available then it is prepared by taking $1 \mathrm{~g}$ basic fuchsin in $200 \mathrm{ml}$ boiling distilled water, then cooled to $50^{\circ} \mathrm{C}$, filtered and $30 \mathrm{ml}$ of $1 \mathrm{~N} \mathrm{HCl}$ added, cooled to room temperature, $1 \mathrm{~g}$ potassium metabisulphite was added allowing it to stand overnight, adding a pinch of charcoal if colour develops and stored in a dark bottle in the refrigerator).

\section{RESULTS AND DISCUSSION}

The entire smear stained pink or magenta colour due to the presence of the eDNA dispersed as small fragments but was darkly stained when these were concentrated in certain regions in the smear when observed under the microscope under 10X and 40X magnification (Fig. 1 \& 2). 


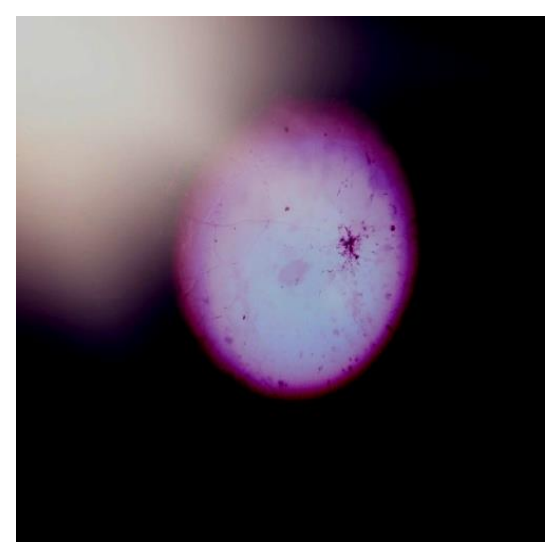

Fig-1-Darkly stained

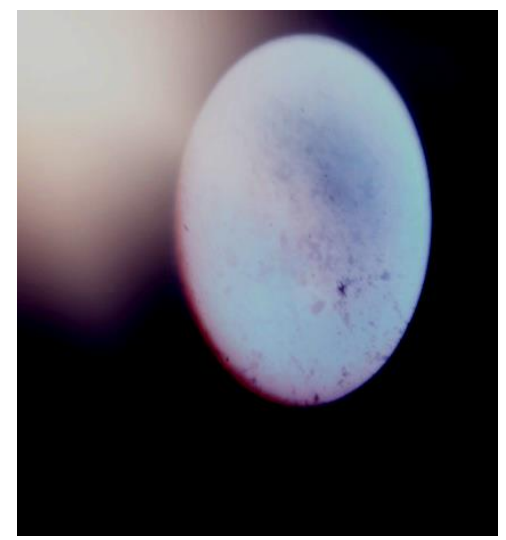

Fig-2 Lightly stained and dispersed

eDNA in the water sample stained with Feulgen (pink colour).

The environmental DNA (eDNA)can be surveyed by different methods that are laborious and time consuming. Many methods are available for the isolation of eDNA like using kits or filtration methods(Rheyda Hinlo et. al. , 2017). Even for species abundance and distribution in ecological studies, methods like passive collection of eDNA using filter membranes was demonstrated by Cindy Bessy et. al, 2021. Environmental DNA can be used for assessing biodiversity in aquatic ecosystems. The assessing of the fish species abundance using eDNA as a tool was helpful in inland fisheries management (Michael J Spear et al, 2020). According to Mathew Seymour (2019) eDNA based research activity is increased in the field of molecular ecology and that it is an emerging new field.

\section{CONCLUSION}

During the present study for the first time the Feulgen stain was used for the water sample to identify the eDNA, the method is used for the selective staining and the localisation of the DNA in the tissues. The method is adopted during the present study so that further studies with isolated eDNA can be carried out. The technique can be applied for the survey of the water bodies for eDNA in the field on a large scale of the lakes for species distribution and their use in genomic, taxonomic and pollutional studies. Therefore, eDNA isolated during the present study with the method described above is a simple, easy, and reliable tool before heading to work on it for further studies using other techniqnies. Further studies of the isolated eDNA are in progress in our laboratory for quantifying and sequencing using latest techniques like next generation sequencing for the identification of fish species in the lakes. The literature on the use of eDNA in India is meagre. Therefore, , extensive studies have to be done for studying species distribution, species abundance and also rare species if any in the water bodies using eDNA.

\section{REFERENCES}

[1]. Cindy Bessy, Simon Neil Jarman,Tiffany Simpson,HayleaMiller,Todd Stewart,John Kenneth \& Oliver Berry,2021-Passive eDNA collection enhances aquatic biodiversity analysis,Volume 4,article Number:236.

[2]. Didier Pont,Alice Valentini,Mathieu Rocle,Anthony Maire,Oliver Delaigue,Pauline Jean,Tony Dejean,2019-The future of fish-based ecological assessment of European rivers:from traditional EU Water Framework Directive 
compliant methods to eDNA metabarcodingapproaches.Journal Of Fish Biology,98,354-366.

[3]. Genetic education,2018-Role of alcohol in DNA extraction .

[4]. Kingsly C Beng \& Richard T.Corlett, 2020Applications of environmental DNA(eDNA) in ecology and conservation: oppurtunities, challenges and prospects.Biodiversity and conservation, Vol29,2089-2121.

[5]. Michael. J Spear,Holly.S. Embke,Patrick..J. Krysan, M. Jake Vander Zanden,2020. Application of eDNA as a tool for assessing fish population abundance.Online library Wiley.com /doi/full/10.1002/edn 3.74.

[6]. Mathew Seymour,2019-Rapid progression and future of environmental DNA research, Communications Biology,Volume 2 article number 80.

[7]. Rheyda Hinlo, Dianne Geeson,Mark Lintermans,Elise Furtan, 2017-Methods to maximise recovery of environmental DNA (eDNA) from water samples,journalpone(Plos One).

\section{Cite this article as :}

Chitra K. Y., "A Simple Technique for the Identification of Environmental DNA (eDNA) in the Water Samples", International Journal of Scientific Research in Science, Engineering and Technology (IJSRSET), Online ISSN : 2394-4099, Print ISSN : 2395-1990, Volume 8 Issue 4, pp. 77-80, July-August 2021. Available at doi : https://doi.org/10.32628/IJSRSET218421 Journal URL : https://ijsrset.com/IJSRSET218421 